\title{
Sun exposure, dressing habits, and vitamin $D$ status in Morocco
}

\author{
Sakhr Dadda ${ }^{1,2}$, Karima Azekour ${ }^{1}$, Fouzia Sebbari ${ }^{1}$, Brahim El Houate ${ }^{2}$ and Bachir El Bouhali ${ }^{1 *}$ \\ ${ }^{1}$ Department of Biology, Faculty of Science and Technique, University Moulay Ismail (UMI), Errachidia, Morocco. \\ ${ }^{2}$ Higher Institute of Nursing and Health Professions of Ouarzazate, Morocco.
}

\begin{abstract}
Sunlight is the main source of vitamin D. Almost $80 \%$ of vitamin D3 is produced in the skin. The region of Draa Tafilalet benefits from long daily sunshine time. As such, vitamin D deficiency should be low in this region. However, dressing habits can highly influence vitamin D status. This study aimed to evaluate sun exposure and its relation to vitamin D status among the general population in the region of Draa-Tafilalet, Morocco. Clinical, biological, and sociodemographic data were obtained from 331 adults visiting local healthcare units during the summers of 2019 and 2020 . Plasma $25(\mathrm{OH}) \mathrm{D}_{2} / \mathrm{D}_{3}$ was measured by immunofluorescence. The prevalence of vitamin D deficiency was $37.5 \%$, while Vitamin D insufficiency represented $56.5 \%$. Most of the studied population (76.4\%) had restricting dressing habits and exposed only their faces. statistic tests showed a correlation of vitamin $D$ levels with daily sun exposure $(r=0.308, p<0.001)$, dressing habits $(\mathrm{p}<0.001)$, age $(\mathrm{r}=-0.141, \mathrm{p}=0.01)$, sex $(\mathrm{p}<0.001)$, physical activity level $(\mathrm{p}=0.003)$, and BMI $(r=-0.298, p<0.001)$. The study showed a high prevalence of vitamin D deficiency in this region. Similarly, it exposed the effects of restricting clothes and low daily sun exposure on vitamin D status.
\end{abstract}

\section{Introduction}

Sunlight is the main source of vitamin D by precursor synthesis in the skin. This production can provide almost $80 \%$ of vitamin D3 (Cholecalciferol). Accordingly, any variation in sun exposure may have a high impact on vitamin D status. At the same time, dietary sources can provide vitamin D2 (Ergocalciferol) in addition to vitamin D3. The main dietary sources of this vitamin are fatty fish, some varieties of mushrooms, or fortified food products [1].

Many hydroxylation reactions occur in the liver and kidney before the activation of vitamin D. A first one happens in the liver producing hydroxyvitamin D $(25(\mathrm{OH}) \mathrm{D})$. A second one happens in the kidney or target tissues producing dihydroxyvitamin $\mathrm{D}(1.25(\mathrm{OH}) \mathrm{D})$. However, the most used metabolite to assess vitamin D status is hydroxyvitamin $\mathrm{D}(25(\mathrm{OH}) \mathrm{D})$. It has a high blood concentration and a long plasmatic half-life compared to other metabolites [2].

Hypovitaminosis D was classically linked to skeletal disorders, such as rickets for children and osteomalacia for adults. However, recent studies associate this deficiency with other chronic diseases, such as cancer or cardiovascular diseases. Vitamin D receptors were identified in many other tissues, suggesting the responsibility of vitamin $\mathrm{D}$ in the manifestation of other diseases [3].

Many factors can influence the skin production of vitamin D, such as determinants, Endogenous characteristics, and behavioral determinants [4].

The first environmental factor relates to geographic location. The latitude can highly influence vitamin D skin production from solar UVB exposure, due to the solar zenith angle. At the same time, UVB radiation reaching Earth's surface can be reduced by the amount of Clouds. Also, Urban areas are related to lower vitamin D concentrations due to a greater preponderance of indoor occupations [4].

Considering endogenous factors, High age is related to low skin production. The vitamin D3 precursor (7dehydrocholesterol) skin concentration lowers with age. At the same time, obesity is linked to lower $25(\mathrm{OH}) \mathrm{D}$ concentrations. Vitamin D is a liposoluble molecule and can be stored in fatty tissues, reducing at the same time the circulating fraction of the molecule [5]. Finally, many genetic alterations can affect the production, transport, or binding of vitamin D metabolites [6].

Behavioral factors can also influence $25(\mathrm{OH}) \mathrm{D}$ skin production. Dressing habits can restrict exposed parts of the body and lower UVB exposition. The occupation of a

* Corresponding author: b.elbouhali@fste.umi.ac.ma 
person can also influence exposition time by indoor or outdoor activities. Also, the use of sunscreen or sun avoidance can restrict vitamin D skin production, due to the concern of skin cancer [4].

In Morocco, several studies showed a high prevalence of hypovitaminosis D [7,8]. The insufficiency in this vitamin can vary between $85.3 \%$ and $91 \%$, considering values of $25(\mathrm{OH}) \mathrm{D}$ lower than $30 \mathrm{ng} / \mathrm{ml}$ [9].

The region of Draa Tafilalet benefits from long daily sunshine time. As such, vitamin D deficiency should be low in this region. However, many factors related to lifestyle can influence vitamin D status. Thus, this study aimed to evaluate daily sun exposure, dressing habits, and its relation to vitamin D status among the general population in this region.

\section{Subjects, material, and methods}

\subsection{Subjects and study design}

This is a cross-sectional study conducted with 331 adults visiting five urban and rural primary health centers of the Draa-Tafilalet region $\left(31.41^{\circ} \mathrm{N}\right.$ latitude). It is a noncoastal oasis region in the East of Morocco. Participants with liver, kidney, or thyroid diseases were excluded from the study $(n=4)$. All the participants gave informed and written consent. The study was approved by the regional directorate of the Ministry of Health of the Draa-Tafilalet region.

\subsection{Data collection}

The data was collected using a structured questionnaire during the summers of 2019 and 2020. collected information related to daily sun exposure, dressing habits, sex, age, physical activity level, and BMI. The World Health Organization (WHO) standards were used to represent BMI groups [1].

\subsection{Biochemical parameters}

The blood samples were taken from peripheral veins in tubes with Ethylene Diamine Tetra-Acetic (EDTA), between $9 \mathrm{~h}$ and $12 \mathrm{~h}$ in the morning. The blood samples were centrifuged for 10 minutes at 5000 RPM. The decanted plasmas were stored in Eppendorfs and frozen at $-20^{\circ} \mathrm{C}$ until analysis (2 days to 2 months). The plasma hydroxyvitamin D [25(OH)D2/D3] was determined by immunofluorescence using an I-chroma TM reader (Boditech Med Inc. Korea) (measurement range: 8 -70 $\mathrm{ng} / \mathrm{ml})$.

the Moroccan Rheumatology Society recommendations for Vitamin D status were considered [11], which corresponds to the international osteoporosis foundation standards [12]. Vitamin D level is considered deficient if $25(\mathrm{OH}) \mathrm{D}$ levels are $<10 \mathrm{ng} / \mathrm{ml}$, insufficient between 10 and $29.99 \mathrm{ng} / \mathrm{ml}$, and normal if $\geq 30 \mathrm{ng} / \mathrm{ml}$.

\subsection{Statistical analysis}

The Shapiro-Wilk test was used to assess the normality of continuous data. Quantitative variables were presented as median and interquartile range. Qualitative data were presented as categories and frequencies. The KruskalWallis or Whitney-Mann tests were used to compare categorical to quantitative data. Associations between quantitative variables were examined by the Spearman test. All statistical analyses were performed using Jamovi (1.2.27). P values less than 0.05 were considered statistically significant.

\section{Results}

A total of 331 subjects participated in this study. The sex ratio was $2 / 5$ (Male/Female) (Table 2). Overall, their median age was 40 years, body mass index (BMI) was $25.7 \mathrm{~kg} / \mathrm{m}^{2}(0.4)$, and daily sun exposure was $1 \mathrm{~h}$. The median $25(\mathrm{OH}) \mathrm{D}_{2} / \mathrm{D}_{3}$ value was $11.8 \mathrm{ng} / \mathrm{ml}$ (Table 1$)$.

Table 1. Correlation of 25(OH)D levels to continuous variables.

\begin{tabular}{lccc}
\hline \multicolumn{1}{c}{ Variable $(\mathrm{n})$} & $\begin{array}{c}\text { Median } \\
\left(\mathrm{IQR}^{\mathrm{a}}\right)\end{array}$ & *r-value & *p-value \\
\hline $\begin{array}{l}\text { 25(OH)D level } \\
(331)\end{array}$ & $\begin{array}{c}11.8 \mathrm{ng} / \mathrm{ml} \\
(8-17.9)\end{array}$ & --- & -- \\
\hline Age $(330)$ & $\begin{array}{c}40 \mathrm{y} \\
(27-51)\end{array}$ & -0.141 & $\mathbf{0 . 0 1 0}$ \\
\hline $\begin{array}{l}\text { Body Mass Index } \\
(330)\end{array}$ & $\begin{array}{c}25.7 \mathrm{~kg} / \mathrm{m}^{2} \\
(22.3-29.6)\end{array}$ & -0.298 & $<\mathbf{0 . 0 0 1}$ \\
\hline $\begin{array}{l}\text { Daily sun } \\
\text { exposure }(329)\end{array}$ & $\begin{array}{l}1 \mathrm{~h} \\
(1-2)\end{array}$ & 0.308 & $<\mathbf{0 . 0 0 1}$ \\
\hline
\end{tabular}

${ }^{\text {a }}$ IQR: Inter-Quartile Range. * Spearman test

The prevalence of vitamin D deficiency was $37.5 \%$, while Vitamin D insufficiency represented 56.5\% (Fig 1). Thus, hypovitaminosis D represents $94 \%$.

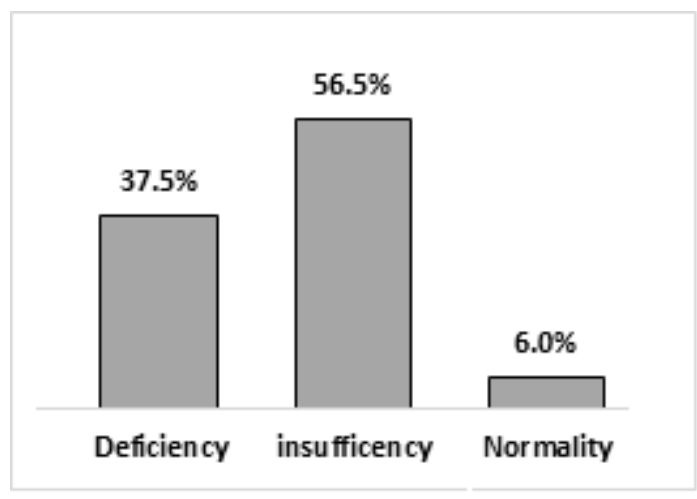

Fig. 1. Vitamin D status based on $25(\mathrm{OH}) \mathrm{D}_{2} / \mathrm{D}_{3}$ levels.

Deficiency: $<10 \mathrm{ng} / \mathrm{ml}$,

Insufficiency: from10 to $29.99 \mathrm{ng} / \mathrm{ml}$

Normality $\geq 30 \mathrm{ng} / \mathrm{ml}$

Regarding dressing habits and physical activity level, most of the population had a restricting clothing style and a normal physical activity with $76.4 \%$ and $68.2 \%$ respectively (Table2). 
Table 2. Correlation of 25(OH)D levels to categorical variables.

\begin{tabular}{lcc}
\hline \multicolumn{1}{c}{ Variable (n) } & Frequency $(\%)$ & $\mathrm{P}$-value \\
\hline Exposed parts (326) & & $* \mathrm{P}<0.001$ \\
Face & $249(76.4 \%)$ & \\
Face + upper limbs & $65(19.9 \%)$ & \\
Face + upper and & $12(3.7 \%)$ & \\
lower limbs & & $* \mathrm{P}=0.003$ \\
\hline Physical activity level & & \\
$(330)$ & $12(3.6 \%)$ & \\
Sedentary lifestyle & $62(18.8 \%)$ & \\
Low activity & $225(68.2 \%)$ & \\
Normal activity & $31(9.4 \%)$ & \\
High activity & $237(71.6 \%)$ & \\
\hline Sex (331) & $94(28.4 \%)$ & \\
Male &
\end{tabular}

*Kruskal-Wallis **Whitney-Mann

Plasma $25(\mathrm{OH}) \mathrm{D}_{2} / \mathrm{D}_{3}$ levels were correlated to all the studied variables. The results showed a high positive correlation to daily sun exposure $(r=0.308, p<0.001)$. So the longer a person is exposed to the sun, the more likely the plasma vitamin D level will be high (fig 2). At the same time, the statistical tests showed a negative correlation of vitamin $\mathrm{D}$ level to age and body mass index ( $\mathrm{r}=-0.141, \mathrm{p}=0.01 ; \mathrm{r}=-298, \mathrm{p}<0.001$ respectively). Thus, higher BMI and age are correlated to lower 25(OH)D values.

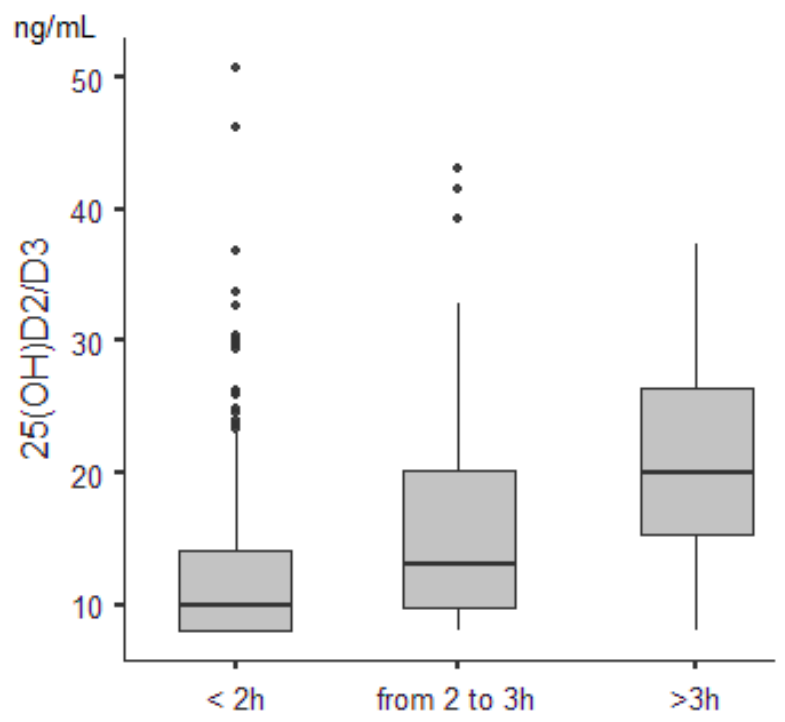

Fig. 2. $25(\mathrm{OH}) \mathrm{D}_{2} / \mathrm{D}_{3}$ levels according to daily sun exposure.

Plasma 25(OH)D was also correlated to dressing habits, sex, and physical activity level $(\mathrm{p}<0.001 ; \mathrm{p}<0.001$; $\mathrm{p}=0.003$ respectively). The distribution of vitamin $\mathrm{D}$ levels regarding dressing habits showed that restrictive clothing can be correlated to low $25(\mathrm{OH}) \mathrm{D}$ values (fig 3 ).

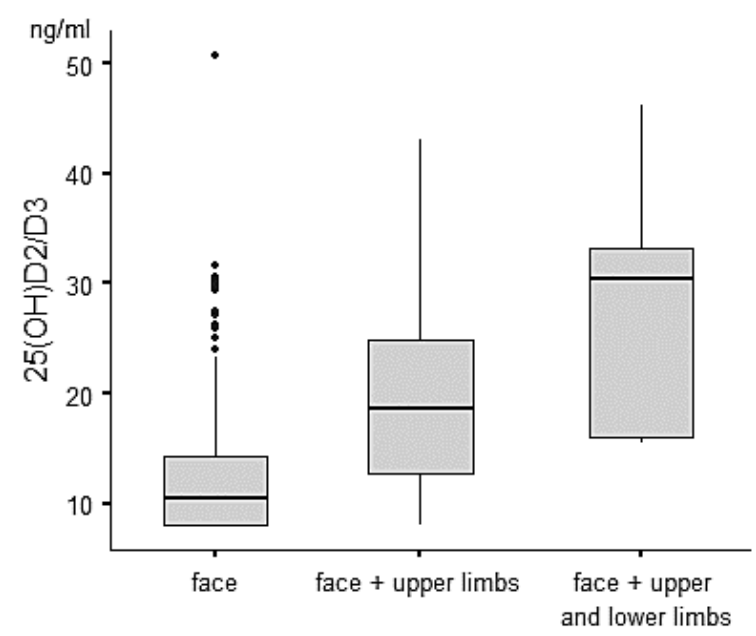

Fig. 3. $25(\mathrm{OH}) \mathrm{D}_{2} / \mathrm{D}_{3}$ levels according to exposed parts of the body.

\section{Discussion}

This study found that hypovitaminosis D is very common in this region of Morocco. The study was conducted during the summer with high sunshine time. At the same time, the latitude of the region $\left(31.41^{\circ} \mathrm{N}\right)$ is not known as a risk factor for low vitamin D skin production. However, the plasma concentrations of serum $25(\mathrm{OH}) \mathrm{D}$ among the study population were lower than expected. This proves that dressing habits and daily sun exposure can highly influence vitamin D status.

The results can be explained by Cultural factors. In conservative societies such as Morocco, the dress code can restrict the exposed parts of the body. $76.4 \%$ of the participants exposed only their faces. Therefore, even with sufficient sunshine, clothing code contributes to vitamin $\mathrm{D}$ deficiency [13]. At the same time, high temperatures during the summer can explain longer indoor dwelling time, lowering the daily sun exposure.

Other factors can influence $25(\mathrm{OH}) \mathrm{D}$ levels such as sex, age, BMI, and physical activity level. In this study, men had significantly higher vitamin D plasma levels. It can be explained by the differences in the dressing code, which allows men to expose more parts of their bodies. Concurrently, men tend to work outdoor more often than women. Thus, they can be more exposed to the sun. Simultaneously, high age and high BMI are linked to lower $25(\mathrm{OH}) \mathrm{D}$ plasma levels. Aging causes the skin to lose its ability to produce pre-vitamin D. So even with sufficient exposition to the sun, the $25(\mathrm{OH}) \mathrm{D}$ can still be low among these persons. Obesity was previously identified as a risk factor for hypovitaminosis D. Obese persons can have low bioavailability of $25(\mathrm{OH}) \mathrm{D}$. The liposolubility of vitamin D promotes its storage in fat cells and simultaneously reduces the circulating fraction. Finally, High activity levels can be linked to outdoor activities with more sun exposure. Other studies presented 
similar findings regarding the influence of physical activities on vitamin D status [14].

The findings of this study agree with studies all over the world regarding hypovitaminosis D [15]. However, questions must be asked about the impact of hypovitaminosis $\mathrm{D}$, provided that the studied population presented no apparent associated pathologies (selfreported). The first point to investigate can be the dosed molecule. Although many persons can have different 25(OH)D levels, they can have close free fractions of vitamin D. So, a more appropriate screening molecule and technique should be considered to reduce disparities among the populations. Another approach can explore the genetic and environmental factors that can influence vitamin $\mathrm{D}$ status. So, with the variety of phenotypes such as skin color and the high difference of sunshine time all over the world, we should not use the same standards to assess vitamin D levels. For example, an African person with darker skin and high UVB exposure may physiologically not have the same plasma vitamin D storage need compared to a north European person with fair skin and low UVB exposition.

\section{Limitations of the study}

The first limit of the study is related to the sex ratio. Male participants represent only $28.4 \%$ of the studied population. Nonetheless, they had significantly higher $25(\mathrm{OH}) \mathrm{D}_{2} / \mathrm{D}_{3}$ levels as presented in other studies $[8,16]$. Accordingly, the sex ratio inadequacy didn't affect the results.

Another issue is related to the storage delay before analysis. The samples were stored for a period between 2 days and 2 months $\left(-20^{\circ} \mathrm{C}\right)$, due to the availability of analytical reagents. As such, there could be variability of plasma levels regarding the storing period. However, studies confirmed that plasma vitamin D levels can be stable after long-term storage at $-20^{\circ} \mathrm{C}$ [17]. Thus, this restriction will not affect our results.

Finally, $25(\mathrm{OH}) \mathrm{D}_{2} / \mathrm{D}_{3}$ levels were analyzed using the immunofluorescence method, which cannot detect values below $8 \mathrm{ng} / \mathrm{ml}$. However, nutrition specialists consider a threshold of $10 \mathrm{ng} / \mathrm{ml}$ or $12 \mathrm{ng} / \mathrm{ml}$ to determine a vitamin $\mathrm{D}$ deficiency [12]. Therefore, the distribution regarding vitamin D status will not be affected.

\section{Conclusion}

The study showed a high prevalence of vitamin D deficiency in this region. Similarly, it exposed the effects of restricting clothes and low daily sun exposure on vitamin D status. Further research should evaluate the impact of hypovitaminosis D on the population's health nationwide and determine the influence of genetic factors on vitamin D status.

\section{Acknowledgments}

This work was supported by the Moulay Ismail University of Meknes, Morocco (grant: UMI-2018)

\section{References}

1. Bouillon R, Carmeliet G. Vitamin D insufficiency: Definition, diagnosis, and management. Best Pract Res Clin Endocrinol Metab; 32(5):669-84 (2018).

2. Jassil NK, Sharma A, Bikle D, Wang X. Vitamin D Binding protein and 25-Hydroxyvitamin D levels: emerging clinical applications. Endocr Pract Off J Am Coll Endocrinol Am Assoc Clin Endocrinol; 23(5):605-13 (2017).

3. Singh P. Treatment of Vitamin D Deficiency and Comorbidities: A Review. J Assoc Physicians India; 66(1):75-82 (2018).

4. Grant WB, Bhattoa HP, Pludowski P. Determinants of Vitamin D Deficiency From Sun Exposure. In: Vitamin D [Internet]. Elsevier; [cited 2020 Apr 26]. p. 79-90 (2018). Available from: https://linkinghub.elsevier.com/retrieve/pii/B978012 8099636000614

5. Rachidi W, Nassar K, Janani S, Mkinsi O. L'hypovitaminose D: Que retenir en pratique? Rev Marocaine Santé Publique [Internet]. [cited 2020 Jun 17]; 4(6) (2017) Available from: https://revues.imist.ma/index.php/RMSP/article/view /9775/5568

6. Bahrami A, Sadeghnia HR, Tabatabaeizadeh S-A, Bahrami-Taghanaki H, Behboodi N, Esmaeili H, et al. Genetic and epigenetic factors influencing vitamin D status. J Cell Physiol.;233(5):4033-43 (2018).

7. Moukal A, Izaabel EH, Farouqi AE, Aghrouch M. Evaluation du statut en vitamine d et sa relation avec les paramètres anthropométriques: cas de la région Souss Massa (Maroc). Int J Innov Appl Stud.;24(4):12 (2018).

8. Laassila S. Statut de la vitamine D chez la population de la région de Meknès-Tafilalt [Thèse de doctorat en médecine]. [Fès]: Université Sidi Mohamed Ben Abdellah Faculté de Médecine et de Pharmacie de Fès. Maroc; (2017).

9. Bour A, Nejjar B. Knowledge about vitamin D: an overview of the prevalence of hypovitaminosis D among Moroccan population. Ann Sci Santé.;1(15):24-31 (2017).

10. WHO. Body mass index - BMI [Internet]. World Health Organization; 2020 [cited 2020 May 11]. Available from: http://www.euro.who.int/en/health- 
topics/disease-prevention/nutrition/a-healthylifestyle/body-mass-index-bmi

11. Abourazzak FE, Khazzani H, Mansouri S, Ali S, Alla $\mathrm{O}$, Allali F, et al. Recommandations de la Société Marocaine de Rhumatologie sur la vitamine D chez l'Adulte. Rev Mar Rhum;13 (2016).

12. Bouillon R. Comparative analysis of nutritional guidelines for vitamin D. Nat Rev Endocrinol;13(8):466-79 (2017).

13. Alhazim M, Littlewood J, Canavan K, Carey P. Sunlight analysis for the Kuwaiti Government dwelling design and effects on householders' health. Energy Procedia;134:894-903 (2017).

14. Fernandes M, Junior W. Association between physical activity and Vitamin D: A narrative literature review. Rev Assoc Médica Bras; 63:550-6. (2017)

15. Van Schoor N, Lips P. Worldwide Vitamin D Status. In: Vitamin D [Internet]. Elsevier; [cited $2020 \mathrm{Feb}$ 17]. p. 15-40 (2018). Available from: https://linkinghub.elsevier.com/retrieve/pii/B978012 8099636000596

16. Nissoul A. Statut de la vitamine D chez les diabétiques type 2 avec ou sans rétinopathie diabétique. [Marrakech. Maroc]: Université Cadi Ayyad. Faculté de médecine et de pharmacie de Marrakech; (2017).

17. Borai A, Khalil H, Alghamdi B, Alhamdi R, Ali N, Bahijri S, et al. The pre-analytical stability of 25hydroxyvitamin D: Storage and mixing effects. J Clin Lab Anal [Internet]. (2019) [cited 2021 Jun 15];34(2). Available from: https://www.ncbi.nlm.nih.gov/pmc/articles/PMC703 1638/ 